\title{
Successful management of a breastfeeding mother with severe eczema of the nipple beginning from puberty
}

Rui Li

Department of Obstetrics and Gynecology, Peking Union Medical College Hospital

\section{Li-Xia Zhang}

Department of Obstetrics and Gynecology, Peking Union Medical College Hospital

Ce Tian

Department of Obstetrics and Gynecology, Peking Union Medical College Hospital

\section{Liang-Kun Ma}

Department of Obstetrics and Gynecology, Peking Union Medical College Hospital

\section{Ying Li ( $\sim 13671217108 @ 163 . c o m)$}

Department of Obstetrics and Gynecology, Peking Union Medical College Hospital

\section{Case Report}

Keywords: atopic dermatitis, breast feeding, breastfeeding counselors

Posted Date: February 21st, 2022

DOI: https://doi.org/10.21203/rs.3.rs-1374906/v1

License: (c) (i) This work is licensed under a Creative Commons Attribution 4.0 International License. Read Full License 


\section{Abstract}

Background Nipple eczema is the most common presentation of atopic dermatitis of the breast, which seriously influences breastfeeding of mothers. We here present a case of severe nipple eczema that started in puberty and received continuous care and interventions during pregnancy, the patient was successful in breastfeeding after the interventions. So the case was to provide a reference for nurses to formulate nursing programs.

Case presentation A 36-year-old woman with 16-weeks of gestation, G1P0, visited the breastfeeding consultation clinic, complaining of excessive nipple secretion, severe itching, and concerns about breastfeeding. Severe nipple eczema was diagnosed. Through continuous monitoring and guidance of the patient, nipple eczema significantly improved, lactating confidence improved, anxiety symptoms reduced, and exclusive breastfeeding was achieved.

Conclusions For lactating women with nipple eczema, breastfeeding consultants should play an important role and provide whole-process and individual guidance.

\section{Background}

Breastfeeding is considered the ideal way to feed infants. It provides optimal nutritional and immune protection for infants, helps mothers and infants bond, and provides significant health benefits for mothers ${ }^{[1,2]}$. According to the World Health Organization, infants should be exclusively breastfed until age 6 months. However, breastfeeding currently faces many obstacles ${ }^{[3]}$. For example, nipple discomfort can frustrate mothers, leading to a reduction in the frequency, duration and even termination of breastfeeding $^{[4,5]}$. Eczema is one of the causes of skin discomfort ${ }^{[6]}$, and occurs in $1 / 10$ population ${ }^{[7,8]}$. When the eczema develops in the nipple, it may aggravate the patient's discomfort or even influence the breastfeeding of mothers.

Eczema (atopic dermatitis) is a chronic inflammatory skin disease characterized by itching, dry skin, erythema, exudation, crusting, and lichenification ${ }^{[8]}$. Eczema most often affects children but also many adults, and can be divided into three types: endogenous atopic dermatitis, allergic contact dermatitis and irritant contact dermatitis ${ }^{[9]}$. Eczema in lactating women is common in the nipples and areola, which is painful, burning and itchy dermatitis, accompanied by redness and swelling, vesicle rupture, scab and exudative papules when acute erythema erupts ${ }^{[10]}$. Repeated scratching can trigger a self-sustaining itchscratching cycle that reduces quality of life.

Eczema of the nipple can occur in female puberty, affect lactation efficiency, and hinder exclusive breastfeeding. Here, we present a case of severe nipple eczema that started in puberty and received continuous care during pregnancy, to provide a reference for nurses to formulate nursing programs.

\section{Case Presentation}


Demographic information

A 36-year-old woman with 16-weeks of gestation, G1P0, visited the breastfeeding consultation clinic, complaining of excessive nipple secretion, severe itching, and concerns about breastfeeding.

Physical examination showed that there were many yellow secretions, and the nipples were cracked and red (Fig. 1).

Medical history

The patient complained that nipple squeezing was performed by family members according to local customs after birth, and skin on the nipple was damaged after squeezing. Until adolescence, the nipple was itchy, red, painful, and chapped, accompanied by occasional exudation. Rubbing the nipples with a towel relieved the itching. The patient did not seek medical treatment because she was concerned that the dermatologist was male. Until marriage, she went to the breast department for medical treatment at the age of 29, but the breast department did not give treatment and medication. The patient used lanolin cream, which could aggravate the chapping and pain.

Psychological evaluation revealed that the patient was anxious and worried about postpartum breastfeeding. Her breastfeeding efficiency was low.

Interventions

(1) Health education: the breastfeeding counselor explained the cause of the disease, in order to reduce her stigma. Dermatologic treatment was suggested. (2) Referral: the breastfeeding consultant referred the patient to a dermatology clinic. The dermatologist prescribed hydrocortisone butyrate cream, polymyxin B ointment, and albolene applied twice daily. (3) Medication guidance and effectiveness monitoring: according to the dermatologist's advice, the breastfeeding consultant implemented health education and urged the patient to take medication regularly. The breastfeeding consultant continued to follow the patient for 23 weeks, paying attention to the nipple eczema and medication status every week. The patient showed significant improvement and the itching symptoms were alleviated. (4) Psychological support: implementation of mindful psychological care and teaching the practice of mindful breathing by focusing on breathing and, relaxing the body. The breastfeeding consultant encouraged the patient to express her true feelings and listened to the main complaints of the patient. The consultant implemented education about breastfeeding, emphasizing the possibility of breastfeeding in patients with nipple eczema, and improving breastfeeding efficiency. (5) Postpartum continuity of care: the patient had a natural birth on November 3, 2021. The breastfeeding instructor implemented one-to-one guidance for the patient in the hospital ward on correct breastfeeding posture, and encouraged intermittent use of Vaseline to moisturize and prevent cracked nipples. After delivery, the breastfeeding instructor provided continuous online guidance and face-to-face visit to the patient.

Outcomes 
(1) After the continuous monitoring and guidance of the patient, the nipple eczema significantly improved before delivery, and breastfeeding confidence increased. (2) During treatment, the breastfeeding consultant encouraged the patient to apply mindfulness therapy, focused breathing, to feel her own body, and regulate her emotions. Finally, the patient accepted the symptoms of eczema and actively treated them. The patient complained of reduced anxiety symptoms. (3) After the patient was discharged from hospital, follow-up visits were conducted to offer guidance on the methods of breastfeeding and breast care, so that the woman could successfully achieve exclusive breastfeeding.

Figure 2 shows that nipple eczema significantly improved 45 days after delivery.

\section{Discussion And Conclusions}

This case raises six outstanding issues that deserve our attention. (1) Clinical nursing evaluation. Systematic assessment is the key to nursing measures. A breastfeeding counselor must obtain a complete skin anamnesis, including history of eczema, psoriasis, or other inflammation. The anamnesis needs to begin in adolescence or even in babyhood. Breastfeeding counselors rule out irritant or allergic contact dermatitis by asking about all detergents, soaps, and topical products used by nursing mothers, and asking mothers about food allergies and adding solid foods to the infant's diet, which may trigger breastfeeding allergic contact dermatitis. If conventional eczema treatment fails within 15-20 days, further pathological examination should be performed to exclude eczema-like carcinoma of the nipple ${ }^{[11]}$.

(2) Medication guidance. Breastfeeding consultants should provide whole-course and individualized medication guidance for parturients, so as to improve medication compliance and enhance medication efficacy. Eczematous papillary dermatitis can be treated with a low-to moderate-strength cortisone ointment twice daily for 2 weeks. Topical corticosteroid ointments of class $\mathrm{V}$ or VI potency are recommended ${ }^{[12]}$. Topical corticosteroids with class I potency should be avoided. If topical therapies are ineffective, oral corticosteroids for less than 3 weeks are acceptable with an interval of 4 hours after each dose in the mothers. If the itch is severe, second-generation antihistamines, such as loratadine, are generally safe. Antihistamines are most effective if eczematous dermatitis has an allergic component. When using antihistamines, mothers should be advised to watch their infants for signs of overexposure, including sedation, tachycardia and dry mouth. Oral doxepin is contraindicated during lactation because it can cause dangerous sedation and respiratory depression in infants ${ }^{[13]}$.

(3) Life coaching. The purpose of breastfeeding guidance is to correct bad breast health habits and eliminate the potential risks of breast diseases. Therefore, breastfeeding counselors should strengthen guidance on patients' lives. As with other types of dermatitis, nipple-specific dermatitis is usually multifactorial. Therefore, breastfeeding counselors need to identify and address each contributing factor. Management should include environmental disinfection in addition to treatment for each infectious cause of mastitis; instruction to place all pacifiers and breast pump shields in the sterilizer ${ }^{[14]}$; and sheets and bras should be washed in hot water. Patients can be instructed to apply moisturizers such as Vaseline $e^{[15]}$. 
(4) Public health education. Our patients was young at the age of onset of nipple eczema, and her family squeezed her nipples at birth, resulting in poor breast health habits and nipple breakage. In rural China, such a situation often occurs, because it is believed that nipple squeezing at birth can cause nipple depression in adulthood, and absence of nipple squeezing can affect subsequent lactation ${ }^{[16]}$. Therefore, breast health promotion in China still needs to be further strengthened. Maternal and child healthcare workers, especially those who work in grass-roots communities, should do a good job of health promotion, to avoid adverse breast hygiene events.

Our patient suffered from nipple redness and pain during puberty, and was ashamed to inform parents and seek medical treatment, which aggravated the symptoms and delayed treatment. This reminds us of the importance of breast education during adolescence. However, previous breast education studies only focused on breast cancer and breast self-examination among adolescents ${ }^{[17]}$. Adolescence is a challenging time for girls, when breast development can be embarrassing and confusing, negatively affecting body image, self-esteem and participation in physical activity. Education on sexual health in school has been shown to increase young people's knowledge and improve attitudes and behavior. However, currently, many international curricula do not provide breast health education beyond adolescent biology ${ }^{[18]}$. Therefore, it is suggested to add breast health education to students' courses to encourage girls to face up to breast development ${ }^{[19]}$. According to the report, the most appropriate age to introduce the topic of breasts is 11 years, which is the average age at which breasts begin to develop in all races ${ }^{[18]}$. Therefore, adolescent breast health should be included in the curriculum of primary schools. Breast health education programs should cover multiple topics such as breast awareness, breast ptosis, breast pain, breast size and breast changes, proper breast support and bra fitting.

(5) Continuity of care. This indicates that medical staff should pay attention to breast health of peripartum women, strengthen education for pregnant women, pay attention to the stigma related to female breast diseases, and encourage eczema patients to seek medical treatment in time. Breastfeeding clinics should play an important role in referring patients to dermatology clinics ${ }^{[20,21]}$ and paying timely attention to their treatment compliance.

In addition, as eczema of the nipple affects breastfeeding, breastfeeding consultants should urge the patients to receive medication according to doctor's advice, in order to reduce the recurrence rate. Breastfeeding consultants should also provide timely monitoring and comprehensive guidance, including psychological guidance.

(6) Focus on mental health. Unbearable itching in patients with nipple eczema increases mental stress and makes them anxious. In particular, for perinatal nipple eczema, breastfeeding efficiency may be lower due to fear of breastfeeding failure after delivery, and this may aggravate the patient's anxiety. With these patients, breastfeeding counselors should pay attention to the patients' emotions, listen to their complaints, implement psychological therapies such as mindfulness and cognitive intervention [22, 23], instruct patients to experience the generation and disappearance of emotions, thoughts, impulses and thoughts, and guide them to accept them objectively without rejecting or criticizing them. Breastfeeding 
counselors should instruct patients to perform breathing exercises to reduce anxiety. Puerpera are instructed to deal with stress in a positive way, carry out mindful introspection, patiently feel the inner body and mind, and allow any emotions, physical feelings and thoughts to fluctuate while ignoring them ${ }^{[24]}$. In addition, positive support is provided to the spouse ${ }^{[25,26]}$, and psychological counseling can be provided when necessary.

In conclusion, eczema of the nipple can affect the health of the female breast, so it is necessary to strengthen health education about the female breast from adolescence. For patients with nipple eczema, breastfeeding consultants should play an important role in providing whole-process and individualized guidance. At the same time, we should pay attention to the change in female psychology and give correct psychological support.

\section{Abbreviations}

G1P0: Gestation 1 Parturition 0.

\section{Declarations}

Ethics approval and consent to participate

The reported patient gave informed consent to the study.

\section{Consent for publication}

Not applicable.

\section{Availability of data and materials}

The datasets used and/or analyzed during the current study are available from the corresponding author on reasonable request.

\section{Competing interests}

The authors declared that they have no any competing interests.

\section{Funding}

This study was funded by: the National Clinical Research Center for Obstetric \& Gynecologic Diseases, Department of Obstetrics and Gynecology, Peking Union Medical College Hospital, Chinese Academy of Medical Sciences \& Peking Union Medical College; and CAMS Innovation Fund for Medical Sciences (CIFMS) (2021-I2M-1-023).

\section{Authors' contributions}


Rui Li conceived and designed the study. All authors identified the study, provided guidance to the patient and wrote the manuscript. All authors read and approved the final version of the manuscript.

\section{Authors' information}

Rui Li, E-mail: liying3487@sina.com

Li-Xia Zhang, E-mail: zhanglixia@pumch.cn

Ce Tian, E-mail: tiancenursing@126.com

Liang-Kun Ma, E-mail: maliangkun@pumch.cn

Ying Li, E-mail: 13671217108@163.com

\section{References}

1. DEL C L, DEL C I. Breastfeeding and the Benefits of Lactation for Women's Health[J]. Rev Bras Ginecol Obstet, 2018,40(6): 354-359.

2. KOH K. Maternal breastfeeding and children's cognitive development[J]. Soc Sci Med, 2017,187: 101-108.

3. FERREIRA H, OLIVEIRA M F, BERNARDO E, et al. Factors Associated with Adherence to the Exclusive Breastfeeding[J]. Cien Saude Colet, 2018,23(3): 683-690.

4. WESTERFIELD K L, KOENIG K, OH R. Breastfeeding: Common Questions and Answers[J]. Am Fam Physician, 2018,98(6): 368-373.

5. SAYRES S, VISENTIN L. Breastfeeding: uncovering barriers and offering solutions[J]. Curr Opin Pediatr, 2018,30(4): 591-596.

6. BELLÙ R, CONDÒ M. Breastfeeding promotion: evidence and problems[J]. Pediatr Med Chir, 2017,39(2): 156.

7. FRAZIER W, BHARDWAJ N. Atopic Dermatitis: Diagnosis and Treatment[J]. Am Fam Physician, 2020,101(10): 590-598.

8. TORRES T, FERREIRA E O, GONÇALO M, et al. Update on Atopic Dermatitis[J]. Acta Med Port, 2019,32(9): 606-613.

9. HELLER M M, FULLERTON-STONE H, MURASE J E. Caring for new mothers: diagnosis, management and treatment of nipple dermatitis in breastfeeding mothers[J]. Int J Dermatol, 2012,51(10): 11491161.

10. KIM J, KIM B E, LEUNG D. Pathophysiology of atopic dermatitis: Clinical implications[J]. Allergy Asthma Proc, 2019,40(2): 84-92.

11. STRENG A, GUTJAHR E, AULMANN S, et al. [Pathology of the nipple-areola complex: I. Paget's disease of the nipple, variants, and differential diagnoses][J]. Pathologe, 2020,41(4): 393-399. 
12. BARRETT M E, HELLER M M, FULLERTON S H, et al. Dermatoses of the breast in lactation[J]. Dermatol Ther, 2013,26(4): 331-336.

13. UGUZ F. A New Safety Scoring System for the Use of Psychotropic Drugs During Lactation[J]. Am J Ther, 2021,28(1): e118-e126.

14. CHIDZIWISANO K, SLEKIENE J, MOSLER H J, et al. Improving Complementary Food Hygiene Behaviors Using the Risk, Attitude, Norms, Ability, and Self-Regulation Approach in Rural Malawi[J]. Am J Trop Med Hyg, 2020,102(5): 1104-1115.

15. RAVEENDRAN R. Tips and Tricks for Controlling Eczema[J]. Immunol Allergy Clin North Am, 2019,39(4): 521-533.

16. SHUANGYAN W, JING L, MENG L, et al. Investigation on the cognition of breast cancer and breast self-examination in middle aged women in rural areas of Jilin province[J]. Nursing of Integrated Traditional Chinese and Western Medicine, 2017,3(11): 34-37.

17. BROWN N, SMITH J, BRASHER A, et al. Breast education for schoolgirls; why, what, when, and how? [J]. Breast J, 2018,24(3): 377-382.

18. TANTON C, JONES K G, MACDOWALL W, et al. Patterns and trends in sources of information about sex among young people in Britain: evidence from three National Surveys of Sexual Attitudes and Lifestyles[J]. BMJ Open, 2015,5(3): e7834.

19. OMRANI A, WAKEFIELD-SCURR J, SMITH J, et al. Breast Education Improves Adolescent Girls' Breast Knowledge, Attitudes to Breasts and Engagement With Positive Breast Habits[J]. Front Public Health, 2020,8: 591927.

20. CUIPING L, JIEYING W. Effect of outpatient counseling and guidance on knowledge and success rate of breastfeeding for primiparas [J]. Chinese General Practice Nursing, 2019,17(16): 2028-2030.

21. QIAOXUAN W, LIYING Y, YUJUN Z, et al. The feelings of mothers had a previous unsuccessful breastfeeding experience attending breastfeeding clinic: a qualitative research[J]. Journal of Nursing Science, 2017,32(18): 42-45.

22. YUANYUAN C, JIAOJIAO Z, CHEN C, et al. A meta-analysis of effect of mindfulness-based intervention on posttraumatic growth in patients with cancer[J]. Chinese Mental Health Journal, 2021,35(02): 113-120.

23. XIAOYUXIANG, ZIWEI J, XIANGNA L, et al. Effects of mindfulness-based stress reduction therapy on cancer-induced fatigue and mindfulness in breast cancer patients [J]. Health Vocational Education, 2021,39(04): 131-133.

24. MINDFULNESS S G. Chinese experts consensus on mindfulness intervention[J]. Chinese Journal of Behavioral Medicine and Brain Science, 2019(09): 771-777.

25. TRICKEY H, THOMSON G, GRANT A, et al. A realist review of one-to-one breastfeeding peer support experiments conducted in developed country settings[J]. Matern Child Nutr, 2018,14(1).

26. FOTIOU C, SIAHANIDOU T, VLASTARAKOS P V, et al. The effect of body and mind stress-releasing techniques on the breastfeeding of full-term babies; a critical analysis of published interventional studies[J]. J Matern Fetal Neonatal Med, 2018,31(1): 98-105. 
Figures

Figure 1 Pre-guided treatment

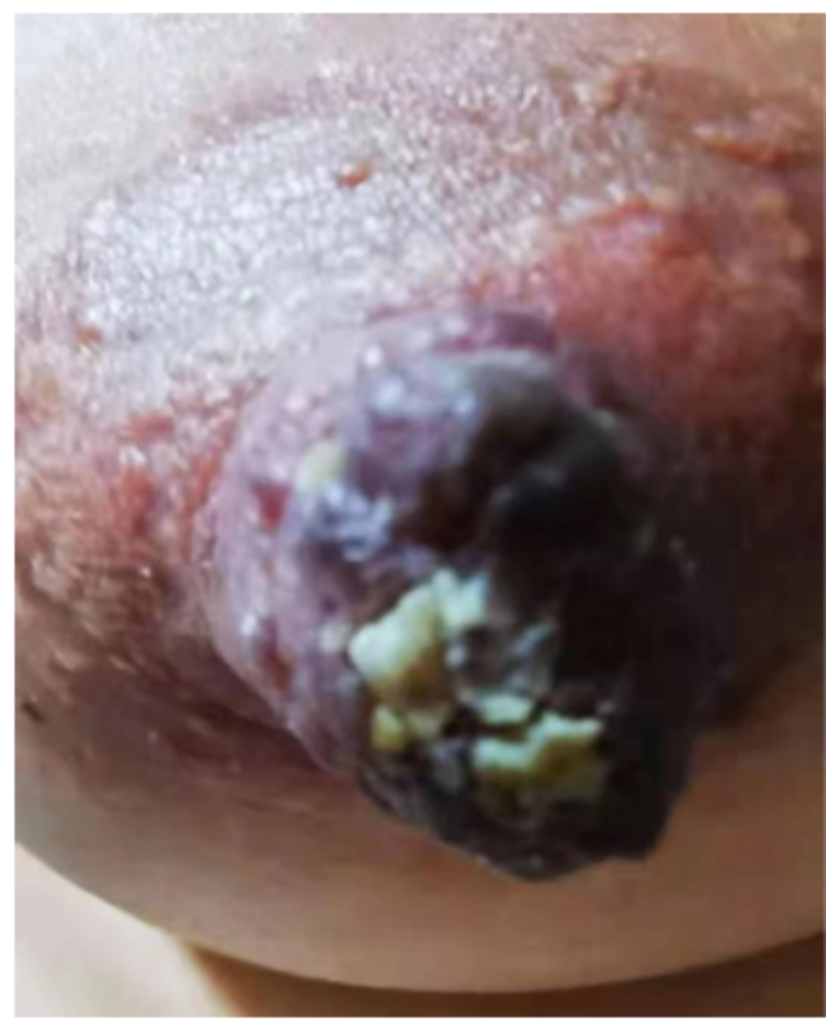

Figure 1

See image above for figure legend 


\section{Figure 2 After guided treatment}

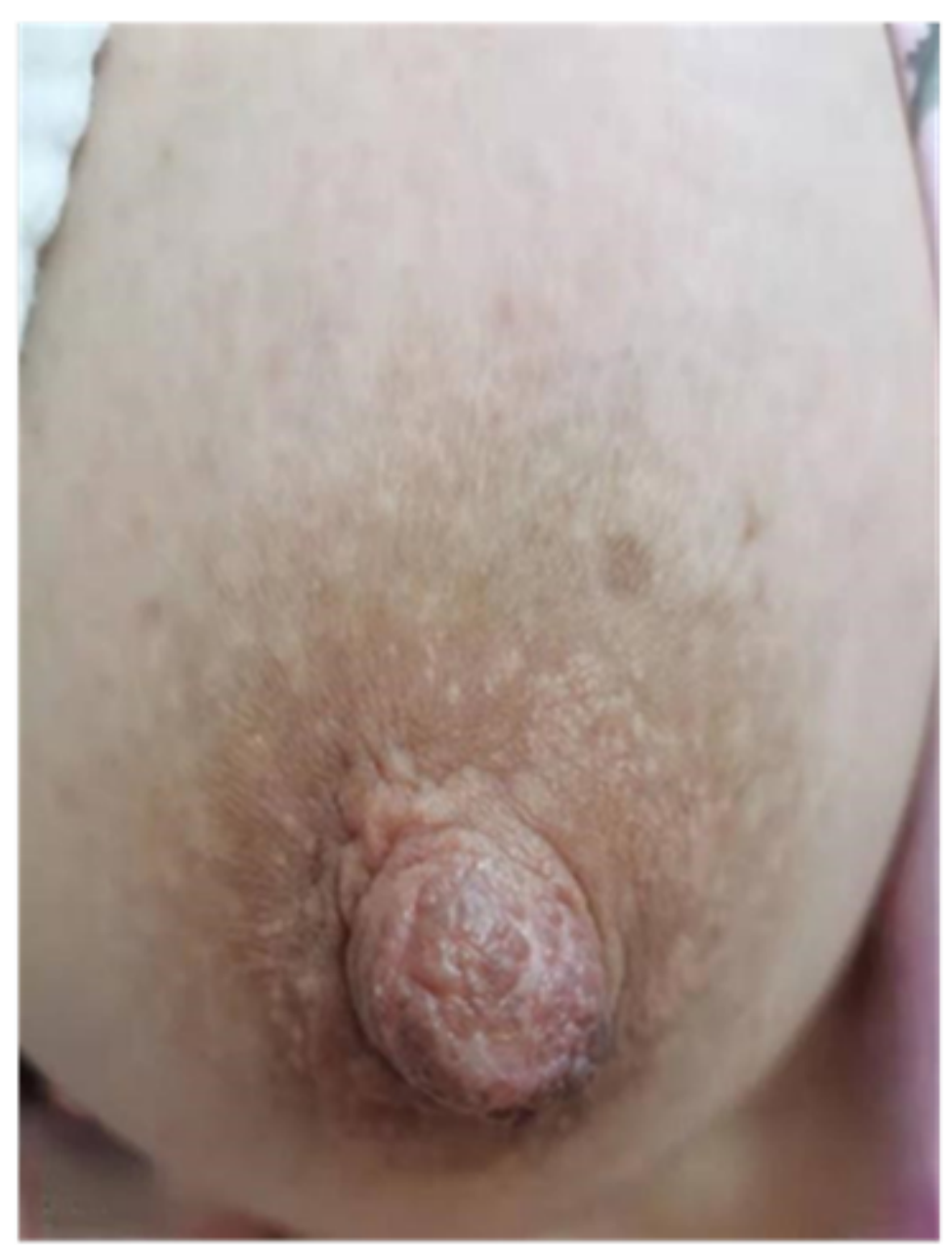

Figure 2

See image above for figure legend 